\title{
LE BARRAGE DE SANTA-LUZIA (PORTUGAL)
}

Situés dans le bassin supérieur du Zezere, affluent de la rive droite du Tage, le barrage et la centrale de Santar-Luzia ont été construits en 1939-1945 par la Compagnie Das Beiras. Barrant une gorge profonde, dans un terrain formé de quartzite, ce barrage voùte $(65 \mathrm{~m}$. environ de hauteur, $12 \mathrm{~m}$. environ d'épaisseur à lat base) crée une retenue utilisable de 45 millions de mètres cubes. Le lecteur s'étonnera de la forme en double voúte que revèt lo couronnement de l'ouvrage. Cette forme particulière, due à M. l'Inspecteur Gónéral Corne a permis d'asseoir solidement les parties hautes du barrage. Gràce à elle, l'appui rive gauche, qu'un rocher fissuré ne permettait pas de fonder directement dans sa partie supérieure, a pu ètre reporté sur des roches compactes situées en retrait.

L'appareillage mécanique et bectrique a largement fait appel a lat technique des constructeurs français, auxquels sont dus :

- les deux vannes-papilion de vidange de fond (diamètre $1 \mathrm{~m} .800$ et $2 \mathrm{~m}$. sous $60 \mathrm{~m}$. de charge),

- les deux vannes secteur automatiques d'évacuation des crues (dimensions ( $\mathrm{m}, 40 \times 3 \mathrm{~m} .40$ ),

- la conduite forcée en tôle soudée, de $1 \mathrm{~m}$. 65 à $1 \mathrm{~m}$. 25 de diamètre, $2.100 \mathrm{~m}$. de long,

- les trois turbines Pelton à axe horizontal à une roue, deux jets, donnant 8.000 ev chacune sous $298 \mathrm{~m}$. de chute.

- les trois transformateurs de 7.000 liva chacun, comportan! trois entroulements avee commulateur a gradins sur la haute tension,

- les disjoncteurs orthojecteurs du poste, ainsi qu'une partie de l'appareillage.

Cette installation, dont la conception et la réalisation ont été en majeure partie l'ouve d'ingénieurs portugais, est l'un des témoignages de l'essci: technique et industriel que prend ce pays, en pariiculier dans le domaine de l'hydroélectricité et des irrigations ; en attendant la réalisation des chutes puissantes de Castelo DO 13One ( $210.000 \mathrm{cv}$ sous $90 \mathrm{~m}$. de chute -875 millions de $\mathrm{m}^{3}$ de retenue) et de Vhanova $(108.000 \mathrm{cr}$ sous $340 \mathrm{~m}$. de chute, $94 \mathrm{mil}$ lions de $\mathrm{m}^{3}$ de retenue), le barrage de Santa-Luzia constitue la principale réserve hydró́lectrique du Portugal.

CH. 